\title{
Ictus isquémico como forma de presentación de una disección aórtica tipo $A$.
}

Type A aortic dissection presented as a stroke mimicker

\author{
Cátia Ribeiro-Santos ${ }^{1}$, Cláudia Antunes ${ }^{1}$, Cátia Faria ${ }^{1}$, Joao Crespo-Santos ${ }^{1}$ \\ ${ }^{1}$ Serviço de Medicina Interna II, Hospital de Santo André, Centro Hospitalar de Leiria
}

\begin{abstract}
Acute aortic dissection is a rare but lethal cardiac disease involving the aorta and it remains a challenge to diagnose and treat. The range of clinical features is extremely variable. Neurologic symptoms are also present in rare cases but often lead to a misdiagnosis because they mimic stroke. We report a case of a 71-year-old male with aortic dissection presented with acute onset altered mental status and left arm weakness. Aortic dissection presented with neurological symptoms is rare and requires high level of suspicion, especially in cases with unusual presentation.
\end{abstract}

Palabras clave: disección aórtica aguda, disección tipo A, síntomas neurológicos, ictus, resultados del tratamiento.

Keywords: acute aortic dissection, type A dissection, neurological symptoms, stroke, treatment outcomes.

\section{INTRODUCTION}

Acute aortic dissection (AAD) is the most common acute aortic syndrome and a severe cardiovascular emergency with high morbidity and mortality ${ }^{1}$. It is more prevalent in males and in the elderly. Hypertension is the main risk factor ${ }^{2}$. Although sudden onset of severe chest or back pain is the most frequent symptom, other various symptoms may be present ${ }^{3}$. Particularly, acute neurologic symptoms at onset of aortic dissection are not only frequent, but often dramatic and may mask the underlying condition ${ }^{1,3}$.

Aortic dissections are usually classified using the DeBakey or Standford classification systems based on anatomical location. In the case reported we use the Stanford classification, which distinguishes two types: type $A$, more frequent and severe, involves the ascending aorta and requires emergency surgery, whereas type B affects the descending aorta ${ }^{4}$.

This paper describes the clinical case of type A dissection with clinical presentation of neurological symptoms and the importance of early diagnosis and timely intervention for type A dissection patients.

\section{CASE REPORT}

A 71-year-old Caucasian male, with past medical history of hypertension and obesity presented to the emergency department (ED) with sudden onset of altered mental status and left arm weakness. The patient was assisted by a pre-hospital emergency medicine team requiring orotracheal intubation and mechanical ventilation support (MVS) because of altered mental status. There was no history of trauma and chest pain. Vital signs on arrival to ED were systolic blood pressure $85 \mathrm{mmHg}$, heart rate of 140 beats/min, temperature $37.1^{\circ} \mathrm{C}$, oxygen saturation $98 \%$ with MVS and $\mathrm{FiO} 231 \%$. On presentation, neurological assessment noted that the patient was arousable to noxious stimuli with no focal deficits and he showed reactive, mydriatic pupils. Cardiovascular examination revealed muffled heart sounds, jugular venous distention (JVD), narrow pulse pressure and increased capillary refill time. Other systemic examinations were unremarkable. The elec-
Figure 1. Baseline CT and CT-angiography of the head (A). Axial plane revealed no acute hypodensity or hemorrhage (B). An axial reconstruction of the anterior circulation with no evidence of large vessel occlusion (C). In a coronal reconstruction the basilar and posterior cerebral arteries showed no occlusions.

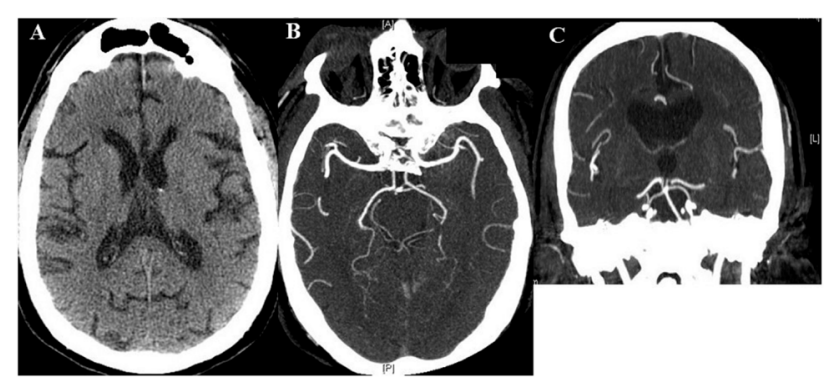

trocardiogram revealed a normal sinus rhythm. Due to history of the present illness and neurological symptoms, the patient was treated as a possible stroke and he underwent our center protocol for managing stroke patients. Thus, we performed baseline computed tomography (CT) and CT-angiography of the head that showed supra-aortic trunks with no hypodensity or hemorrhage and no evidence of large vessel occlusion (Figure 1). However, the patient worsened with progression to hemodynamic instability. Based on these clinical findings, acute aortic syndrome or pulmonary embolism were suspected and an emergency CT pulmonary angiography was done, revealing type A dissection (Figure 2A, $2 \mathrm{~B}$ and $2 \mathrm{C}$ ) from the ascending aorta until both renal arteries. Furthermore, a hemopericardium (Figure 2D) was also noted and the anteroposterior chest $X$-ray showed widening of the mediastinum. Bedside ultrasound revealed massive pericardial effusion with signs of cardiac tamponade. Routine laboratory studies were unremarkable. Faced with the diagnosis of AAD with cardiac tamponade criteria, the patient was transferred to a cardiothoracic surgery referral center and urgently submitted to surgical repair with replacement of the ascending aorta. Subsequently, after prolonged hospitalization, the patient was discharge with 
Figure 2. Chest CT-angiography. Coronal plane (A and $\mathrm{C}$ ) and axial reconstruction $(\mathrm{B})$ revealing an ascending type $\mathrm{A}$ aortic dissection showing the intimal flap (D). In an axial plane aortic dissection revealed pericardial effusion.
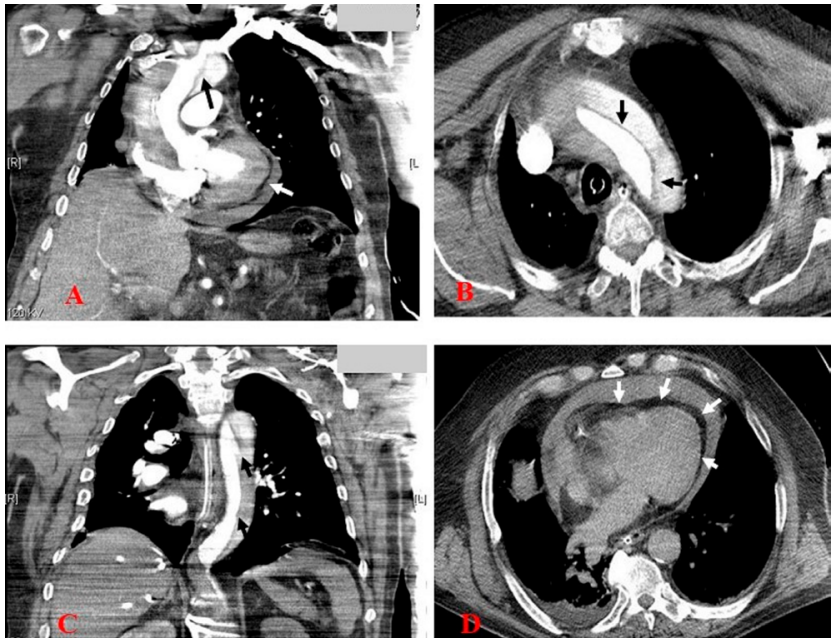

neurological recover without compromised cardiac function and referral to motor rehabilitation program.

\section{DISCUSSION}

Acute aortic syndromes are life-threatening cardiovascular emergencies affecting 3 to 6 per 100000 individuals a year ${ }^{1,5}$, and include aortic dissection, intramural aortic hematoma, penetrating aortic ulcer, and aortic rupture. Approximately $75 \%$ of dissections occur in those aged $40-70$ years and $70 \%$ have hypertension, an important predisposing factor ${ }^{1,2}$. AAD occur when either a tear or an ulcer allows blood to penetrate from the aortic lumen into the media or when a rupture of vasa vasorum causes a bleed within the media4.

Although $A A D$ classically produces sudden onset of severe chest pain that often has a tearing quality, no sign or symptom can positively identify AAD. The clinical presentation is highly unspecific and an estimated $38 \%$ of AAD are missed on initial evaluation".

In aortic dissections, the frequency of neurological symptoms ranges from $15-40 \%{ }^{3}$, and in half of the cases they may be transient. Indeed, major brain injury (i.e. coma and stroke) at the onset of dissection is a complication in 10\% of type $\mathrm{A}$ acute aortic dissection. Arch vessel involvement was more frequent among patients with stroke $e^{6}$.

At hospital presentation, one of the most ominous findings on physical examination is hypotension and it is associated with neurological deficits, altered mental status, myocardial and mesenteric ischemia, limb ischemia, or death in $55 \%$ of patients ${ }^{7}$. Pericardial effusion alone is an independent predictor of mortality and up to one-third of patients with a large pericardial effusion will progress to cardiac tamponade with shock occurring in $15 \%$ of type $A A A D^{8,9}$. AAD can be treated surgically or medically. Emergency surgical correction is the preferred treatment for Stanford type A ascending aortic dissection ${ }^{4,10}$. This case illustrates the dominance of neurologic symptoms in the early stage of $A A D$, which may make its early diagnosis difficult. However, in our case, the diagnosis of AAD was established based on clinical findings, physical exam and CT pulmonary angiography as diagnostic workup. Our patient had no pain and did not exhibit any of the classic signs of aortic dissection. On the other hand, the physical exam reveals Beck's triad of hypotension, JVD and muffled heart sounds, making cardiac tamponade the most likely etiology. The presented case emphasizes the importance of highlighted the clinical features of AAD which may be present together with neurological symptoms mimicking stroke or others neurological symptoms.

\section{REFERENCES}

1. Evangelista A, Isselbacher EM, Bossone $E$, et al. Insights From the International Registry of Acute Aortic Dissection: A 20-Year Experience of Collaborative Clinical Research. Circulation. 2018;137(17):1846-1860.

2. Howard DP, Sideso E, Handa A, Rothwell PM. Incidence, risk factors, outcome and projected future burden of acute aortic dissection. Ann Cardiothorac Surg. 2014;3(3):278-284.

3. Gaul C, Dietrich W, Erbguth FJ. Neurological symptoms in aortic dissection: a challenge for neurologists. Cerebrovasc Dis. 2008;26(1):1-8.

4. Erbel R, Aboyans V, Boileau C, Bossone E, Bartolomeo RD, Eggebrecht $\mathrm{H}$ et al. 2014 ESC Guidelines on the diagnosis and treatment of aortic diseases: Document covering acute and chronic aortic diseases of the thoracic and abdominal aorta of the adult. The Task Force for the Diagnosis and Treatment of Aortic Diseases of the European Society of Cardiology (ESC) [published correction appears in Eur Heart J. 2015 Nov 1;36(41):2779]. Eur Heart J. 2014;35(41):2873-2926.

5. Olsson C, Thelin S, Ståhle E, Ekbom A, Granath F. Thoracic aortic aneurysm and dissection: increasing prevalence and improved outcomes reported in a nationwide population-based study of more than 14,000 cases from 1987 to 2002 Circulation. 2006;114(24):2611-2618.

6. Bossone E, Corteville DC, Harris KM, et al. Stroke and outcomes in patients with acute type A aortic dissection. Circulation. 2013;128(11 Suppl 1):S175-S179.

7. Shono Y, Akahoshi T, Mezuki S, et al. Clinical characteristics of type A acute aortic dissection with CNS symptom. Am J Emerg Med. 2017;35(12):1836-1838.

8. Lee SJ, Kim JH, Na CY, et al. Eleven years of experience with the neurologic complications in Korean patients with acute aortic dissection: a retrospective study. BMC Neurol. 2013;13:46.

9. Bossone E, Pyeritz RE, Braverman AC, et al. Shock complicating type A acute aortic dissection: Clinical correlates, management, and outcomes. Am Heart J. 2016;176:93-99.

10. Girdauskas E, Kuntze T, Borger MA, Falk V, Mohr FW. Surgical risk of preoperative malperfusion in acute type A aortic dissection. J Thorac Cardiovasc Surg. 2009;138(6):1363-1369. 